\title{
We need radical change in how we produce and consume food
}

\author{
Peter Horton ${ }^{1}$ \\ Received: 10 October 2017 / Accepted: 9 November 2017 / Published online: 20 November 2017 \\ (C) The Author(s) 2017. This article is an open access publication
}

Keywords Agri-food system $\cdot$ Sustainability $\cdot$ Policy

\section{Introduction}

Recently, two papers were published that, in different ways, illustrate the huge challenges we face in delivering global food security. In the first, it was shown how nearly half of the greenhouse gas emissions from producing a loaf of bread arise from the nitrogen fertiliser used to drive wheat cultivation (Goucher et al. 2017). With over 100 million tonnes of such fertiliser used annually to support global food production, and the other impacts that arise such as pollution of water courses, the unsustainability of modern agriculture is exposed. In a second paper, the interconnectedness of the agri-food system was elaborated and a compelling case presented for joined-up thinking when devising future policy. This should be one that analyses together environment, land-use, food production, food consumption and human health. Futhermore, it should be one that fully considers the development and expression of agri-technology in the context of the complex cultural, political, ethical and economic tensions that arise (Horton et al. 2017). These two papers lead to the conclusion that only a radical change in the way we produce and consume food will deliver a sustainable and just global agri-food system. In this article the nature and causes of the problem are identified, and possible solutions defined.

\section{Agri-food system failures}

The Green Revolution of the post-World War II era has rightly been hailed as a huge achievement for humankind. Transformation in plant breeding coupled with development of an array of fertilisers and other agrochemicals and

Peter Horton

p.horton@sheffield.ac.uk

1 Grantham Centre for Sustainable Futures and Department of Molecular Biology and Biotechnology, University of Sheffield, Sheffield S10 2TN, UK mechanisation of agronomic practice brought about massive increases in the yields of the major cereal crops, saving millions of lives. It led to an industrialisation of agriculture which has enabled the development of a complex global food business that delivers a wide choice of safe, nutritious and affordable food to billions of people. However, this industrialisation of food production has had significant and increasingly worrying negative environmental and social consequences.

Most importantly, this industrial agri-food system model requires ever-increasing levels of production at the lowest possible economic cost. It is energy intensive, emitting one third of all greenhouse gases (Tubiello et al. 2015) - it is no exaggeration to state that industrial agriculture turns oil into food (Walker 2009). In doing so, it has other serious environmental impacts: destruction of forests and grasslands for new agricultural land, a major cause of biodiversity loss (Tilman et al. 2017); depletion of non-renewable resources such as ancient ground water (Dalin et al. 2017); pollution of land, water courses and oceans by agrochemicals and animal waste (Zhang et al. 2015); and degradation of the soil upon which it totally depends (Montgomery 2007). Fundamentally, intensive agriculture has neglected and even disrupted the biology and natural capital on which the food production system had been historically based. It has also been argued that, because increasingly efficient cereal production was at the expense of crop diversity, it has contributed to high levels of malnutrition, as well as giving rise to negative social and economic changes (Pingali 2012). Moreover, gross inequality in access to food across the globe has persisted, with nearly one billion people underfed in developing countries (FAO 2014) but ironically, also at the same time, excessive consumption in the developed world (Ng et al. 2014). In conclusion, the current agri-food system is not fit for purpose - it is a flawed way to provide food in both developed and developing countries.

The direction of governments' policies to agriculture, agricultural subsidies and agricultural research perpetuate this industrial model, absorbing environmental concerns into the 
idea of sustainable intensification (Garnett et al. 2013), and creating the illusion that to solve "food security" there just needs to be more of the same, but done sustainably. Massive 20,50 or $100 \%$ increases in crop yield are advocated, figures routinely quoted to justify plant science research or denote impact of research publications. Whilst improvements in yield undoubtedly will benefit global food production, this will be only a part of the answer (Foley et al. 2011). Moreover, sustainable intensification capable of delivering yield increases on this scale remains an unproven hypothesis, not yet a blueprint for global food production. The model also gives rise to an assumption that solutions to global health and international development issues are similarly dependent on such technology-led yield increases. Antagonism to this agri-food model leads many to look to the past for solutions, but often do so through "rose-tinted glasses". We cannot produce enough food by going back to pre-industrial processes, and we should not discount the potential of modern technological advances. Organic agriculture in its strictest interpretation will never feed our growing population adequately or indeed sustainably (Doberman 2012). A radical rethink of the whole agri-food system is needed, from production and consumption, to policy and legislation. We need to be brave, but to ensure global food security for the next generation, this is a challenge we must face now. In order to do this, we must first define the root causes of the problems, then evaluate the possible solutions before finally considering how to enact them in political and social terms.

\section{The causes}

- Food provision is driven by a market economic model that depends upon continuous maximisation of growth in consumption (and hence production). Being dependent upon intensive fertilisation from fossil-fuel driven nitrogen fixation it is intrinsically unsustainable because it breaks the natural biological nitrogen cycle. Resource cycles of carbon and phosphorus are also incomplete, and ultimately limits to net primary productivity imposed by the laws of chemistry and physics are reached (Running 2012).

- The agri-food system is dominated by a small number of large global businesses who relentlessly pursue growth and monopoly, whilst absorbing and hijacking trends towards sustainable and healthy food, and who exert pressure on producers to supply food at low cost, to use agrochemicals and so re-inforce the industrial model.

- High supply chain throughput of production and consumption inevitably leads to waste, particularly by the retailer and the consumer, whilst reducing the resilience necessary to cope with global shocks and gross disruption caused by the effects of climate change and plant pests and diseases.
- In the developed world, food is regarded as a consumer item rather than a basic human need, underpinning excessive levels of consumption. Food is advertised and marketed as such, becoming the focus of TV shows, social media and newspaper columns. Food is available 24/7 in supermarkets, takeaways and restaurants. A consequent emphasis on visual appearance of food leads to waste and excessive, unnecssary (and mostly plastic) packaging.

- Food retailing exploits the inherent human physiological desires to consume high calorie food leading to consumption of unhealthy foods, whilst food manufacturers consistently resist attempts to introduce regulations to curb such consumption.

- The inclusion of foodstuffs in global commodity markets leads to many perverse outcomes such as unforeseen land use changes (Lim et al. 2017) and excessive supply (and low price) of often unnecessary and unhealthy food products and additives.

- The omnivorous human diet drives the eating of meat, which is amplified by a host of cultural and social drivers, and exploited by aggressive marketing by the agri-food industry. Meat production is resource inefficient, demands large land areas and adds significantly to greenhouse gas emissions, whilst its consumption contributes to global epidemics of non-communicable disease.

- In order to maximise yield (and profit) agriculture focusses upon a relatively small number of genotypes of a small number of crops. In doing so, potentially more resilient and highly nutritious crops are discarded or ignored.

- Globalisation, which in theory provides for poverty relief through trade, in practice often diverts local agriculture and land use towards food exports to developed countries. The environmental impacts of the food consumed in developed countries are hence exported to developing countries.

- None of the external environmental, social and health penalties of the agri-food system are costed, and there is no mechanism by which responsibility for them is allocated and/or shared between different parts of supply chains.

- Despite the industrialisation of agriculture and its dependence on technology, there has been a failure to embrace those new technologies such as genetically modified crops or new ideas about soil conservation, which could increase the sustainability of food production.

- Well intentioned government policies, such as farm subsidies or food industry incentives, which aim to address environmental and health issues often fail because of reluctance to alienate various sectors of the agri-food industry.

- Research and policy on agri-food is compartmentalised, failing to recognise the inextricable link between environmental health and human health (Tilman and Clark 2014). 


\section{The solutions}

An assertive new vision for agriculture, food business and health needs to be forged. It should entail as its first principles the following:

- A commitment by governments of all countries to implement agri-food policies that will help deliver the United Nations Sustainable Development Goal, "Zero Hunger".

- Recognition by governments that environment, agriculture, food and public health are an integrated system, that has to be considered as a whole.

- Social aspects of the agri-food system, such as equality of access, culture, ethics and justice should not be secondary to free market economics and technology.

- Consumer action and government policy have to work together to bring about change, curtailing and redirecting the motivations of the agri-food businesses and their shareholders.

There should be a concordat on agri-food policy with all stakeholders involved and with legally binding obligations. Procedures should be developed that combine and integrate scientific evidence obtained by methods such as Life Cycle Assessment with sociological indicators in a new approach to evidence-based agri-food policy making (Horton et al. 2017). Such a concordat could recommend a number of interventions and innovations such as the following 10-point plan:

1. A pledge to make sure all people are aware that a diet, in terms of the type and amount of food consumed, that is good for health is also of critical importance for preserving our environment, conserving biodiversity and combatting global warming. This campaign, harnessing everything from social media to food labelling, has to hit home the unsustainability of the current agri-food system, but should also build on current successes (e.g. public awareness of food waste and the dangers of pesticides), and be both positive and optimistic, offering information to enable sustainable food choices.

2. High profile, well-resourced and sustained national and international debate about the production and consumption of meat and other foods derived from livestock should be initiated to find imaginative policies that will deliver reduced production without excessive price increases to the consumer and without damaging farming businesses. Simultaneously, research into increasing the sustainability of production should continue, such as reducing ruminant methane production.

3. Incentives in agriculture should encourage the environmental and health linkage and promote sustainable practices, such as reducing fertiliser use and increasing soil health
4. Legislative powers need to be used when necessary to mandate by law adherence of agri-businesses to indicators of sustainable practice, including reduction of all the environmental impacts of food production, promotion of human health and elimination of operations which lead to food waste.

5. Policies need to be developed that accommodate the probable increase in food prices that will result from such sustainable practices.

6. Trade agreements and national agri-food actions, including research and development, should be designed to deliver a global agri-food system that is just for all people in all countries.

7. Research into exploitation of the huge diversity of foodproducing plants is needed with a view to improving production resilience and human nutrition, together with research and development actions to explore the use of novel sources of food protein.

8. Agricultural research should be directed towards understanding how to maintain outputs with reduced inputs. To meet this objective, highly productive and more resource-efficient crop varieties should be developed through the most efficient methods, including modern methods of gene editing. Simultaneously, investigations of innovative agronomic practices should be given equal priority. Such research needs to engage with, and meet the needs of, small-scale farmers throughout the world, not just the large agri-businesses.

9. The development of large numbers of smaller sustainable farming businesses should be stated targets of governments' policies (Trudge 2016). Co-operatives and mixed function farms, perhaps growing cereals and vegetables along with livestock, and linked to markets and food outlets could form an important part of the agricultural sector. Sharing of expertise and knowledge, and employment of the new technology will make these unlike the old traditional farming model: whilst the principles of organic farming will be harnessed so will $\mathrm{GM}$, remote sensing, and innovations in optimisation, mechanisation and robotics. Circular economy concepts should be the norm, with new technologies to fully utilise non-food outputs and recycle agricultural, food and human waste.

10. Non-traditional types of agriculture, including urban agriculture should become a target for new research and investment. This means not only small scale enterprises that serve mostly a social good but also using these same new technologies to enable significant proportions of food to be grown. Other approaches could include: indoor vertical farming using solar powered LED lighting and environment control; roof top gardens; hi-tech greenhouses bordering urban areas on wasteland; and automated garage or kitchen appliances producing high 
value food in the home, in the workplace and in schools and colleges.

\section{Prospects for a sustainable food future}

Much of the knowledge and many of the technologies required to deliver the above changes either exist or only need development for application. Lack of knowledge and technology are not the principal problems. The problem is thinking that the solutions are purely technical, a philosophy that has dominated agri-food research for the last century and given rise to the failed policies that have resulted. But the solutions to the food security problem are not purely technical ones that can simply be applied in a linear manner (DeFries and Nagendra 2017). There has to be a realisation of the complexity, diversity, connectivity and unpredictability of the agrifood system - one that involves all the features of a biological ecosystem, the physical geography, the climate and not least human behaviour and the vastly complicated global socioeconomic political system in which we live (Horton et al. 2017). Each of the 10 suggested changes need to be empirically tested in specific local contexts, and knowledge gained fed back into decision making - what are the effects, do they bring about the desired change, are the changes sustained, are there unforeseen side effects, are they scalable etc. Testing, evaluation and implementation require unprecedented levels of collaboration across different sectors, with sharing of data and information and total transparency. Somehow, all stakeholders need to be engaged. The danger is that the level of complexity and the degree of collaboration required is so daunting that either there is recourse to the previous (failed) simplistic technical approaches or there is complete paralysis and inaction. Thus, in order that a new sustainable agri-food system is put in place, it is necessary to work through how to formulate the policies necessary for such change, and how to implement them in a way that reconciles the multiple diverse interests of stakeholders. That is the challenge. In the $\mathrm{UK}$, this challenge is recognised in recent reports from various organisations (e.g WRAP 2017; GFS 2017). But, because food is ultimately highly personal and cultural, embedded with emotion and preference, it is through citizen pressure that such change will be initiated (Horton et al. 2016), although studies suggest also the huge importance of political leadership to carry them forward (Amel et al. 2017). Whether such leadership will emerge remains to be seen.

Acknowledgements The author wishes to thank Professors Duncan Cameron, Peter Jackson and Tony Ryan OBE for the many discussions that provoked the writing of this article.
Funding $\mathrm{PH}$ is supported by a generous gift from the Grantham Foundation for the Protection of the Environment, which supports the Grantham Centre for Sustainable Futures in which he works.

Compliance with ethical standards

Competing interest I have no competing interests.

Open Access This article is distributed under the terms of the Creative Commons Attribution 4.0 International License (http:// creativecommons.org/licenses/by/4.0/), which permits unrestricted use, distribution, and reproduction in any medium, provided you give appropriate credit to the original author(s) and the source, provide a link to the Creative Commons license, and indicate if changes were made.

\section{References}

Amel, E., Manning, C., Scott, B., \& Koger, S. (2017). Beyond the roots of human inaction: fostering collective effort toward ecosystem conservation. Science, 356, 275-279.

Dalin, C., Wada, Y., Kastner, T., \& Puma, M. J. (2017). Groundwater depletion embedded in international food trade. Nature, 543, 700 704.

DeFries, R., \& Nagendra, H. (2017). Ecosystem management as a wicked problem. Science, 356, 265-270.

Doberman, A. (2012). Getting back to the field. Nature, 485, 176-177.

FAO. (2014). State of food insecurity in the world. Rome: Food and Agriculture Organization of the United Nations.

Foley, J. A., et al. (2011). Solutions for a cultivated planet. Nature, 478, $337-342$.

Garnett, T., et al. (2013). Sustainable intensification of agriculture: premises and policies. Science, 341, 33-34.

GFS. (2017). Game changing developments in the context of food security and future research priorities. https://www.foodsecurity.ac.uk/.

Goucher, L., Bruce, R., Cameron, D., Koh, S. C. L., \& Horton, P. (2017). Environmental impact of fertiliser embodied in a wheat-to-bread supply chain. Nature Plants, 3, 17012.

Horton, P., Koh, S. C. L., \& Shi Guang, V. (2016). An integrated theoretical framework to enhance resource efficiency, sustainability and human health in agri-food systems. Journal of Cleaner Production, $120,164-169$.

Horton, P., et al. (2017). An agenda for integrated system-wide interdisciplinary agri-food research. Food Security, 9, 195-210.

Lim, F. K. S., Carrasco, L. R., McHardy, J., \& Edwards, D. P. (2017). Perverse market outcomes from biodiversity conservation interventions. Conservation Letters. https://doi.org/10.1111/conl.12332.

Montgomery, D. R. (2007). Soil erosion and agricultural sustainability. Proceedings of the National Academy of Sciences of the United States of America, 104, 13268-13272.

$\mathrm{Ng}$, M., et al. (2014). Global, regional, and national prevalence of overweight and obesity in children and adults during 1980-2013: a systematic analysis for the global burden of disease study 2013. The Lancet, 384, 766-781.

Pingali, P. L. (2012). Green revolution: impacts, limits, and the path ahead. Proceedings of the National Academy of Sciences of the United States of America, 109, 12302-12308.

Running, S. W. (2012). A measurable planetary boundary for the biosphere. Science, 337, 1458-1459.

Tilman, D., \& Clark, M. (2014). Global diets link environmental sustainability and human health. Nature, 515, 518-522.

Tilman, D., Clark, M., Williams, D. R., Kimmel, K., Polasky, S., \& Packer, C. (2017). Future threats to biodiversity and pathways to their prevention. Nature, 546, 73-81. 
Trudge, C. (2016). Six steps back to the land. Why we need small mixed farms and millions more farmers. Cambridge: Green Books.

Tubiello, F. N., et al. (2015). The contribution of agriculture, forestry and other land use activities to global warming, 1990-2012. Global Change Biology, 21, 2655-2660.

Walker, D. A. (2009). Biofuels, facts, fantasy, and feasibility. Journal of Applied Phycology, 21, 509-517.

WRAP (2017). Food futures from business as usual to business unusual. http://www.wrap.org.uk/content/food-futures.

Zhang, X., et al. (2015). Managing nitrogen for sustainable development. Nature, 528, 51-58.

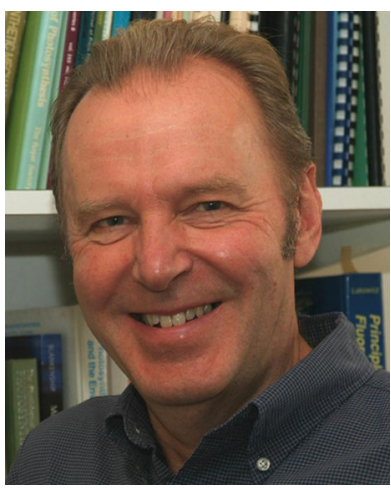

Professor Peter Horton FRS is Emeritus Professor of Biochemistry in the Department of Molecular Biology and Biotechnology at the University of Sheffield. Graduating with a BA in Biology in 1970, he holds a D.Phil. and D.Sc. all from the University of York. After postdoctoral training at Purdue University, he was appointed as Assistant Professor at the State University of New York at Buffalo in 1975. He then took up the post of Lecturer in Biochemistry at the University of Sheffield in 1978, was promoted to Reader in 1984 and to Professor in 1990. He was Director of the Robert
Hill Institute for Photosynthesis Research from 1989 until 2003 and was elected Fellow of the Royal Society in 2010. He is a plant biologist with expertise in photosynthesis now carrying out interdisciplinary research aimed at delivering a global agri-food system that is sustainable, resilient and just. He considers how an integrated analytical view of complete food supply systems will enable interventions that simultaneously reduce the adverse environmental impacts of food production, increase resource-use efficiency and promote human health. This research forms a part of his role as Chief Research Advisor to the Grantham Centre for Sustainable Futures, which aims to build a fairer world and save natural resources for future generations through interdisciplinary research, postgraduate training and external engagement. His previous research on the regulation of the light-dependent reactions of photosynthesis, the process by which green plants use sunlight to make carbohydrates from carbon dioxide and water is widely recognised for integrating knowledge from the molecular to the environmental level. His investigations revealed the molecular transformations used by plants to efficiently exploit limited light whilst also protecting them from excess light through its dissipation as heat. This knowledge now provides ways to produce crops that are better adapted to harsh environments and extreme climatic conditions. Furthermore, his prediction that this photoprotective mechanism could be re-optimised to allow crop plants to photosynthesise more under favourable but fluctuating conditions is being confirmed by recent research 